\title{
PEMODELAN MERDEKA WALK TERKAIT HUBUNGANNYA DENGAN LAPANGAN MERDEKA SEBAGAI RUANG TERBUKA PUBLIK
}

\author{
Yunus Boy Ari Shandi (1), Anna Lucy Rahmawati S.T, M.T. ${ }^{(2)}$, Putri Napitupulu S.T.,M.T. (3)
}

(1) Mahasiswa, Prodi Arsitektur, Fakultas Teknik, Universitas Katolik Santo Thomas Sumatera Utara

(2) Staff pengajar, Prodi Arsitektur, Fakultas Teknik, Universitas Katolik Santo Thomas Sumatera Utara Email : lucyra7011661@gmail.com

(3) Staff pengajar, Prodi Arsitektur, Fakultas Teknik, Universitas Katolik Santo Tthomas Sumatera Utara Email : putriN70@gmail.com

\begin{abstract}
It is true that Merdeka Square is accessible to everyone, can be used for various activities. In the context of behavior, space is said to be open if it allows people to act freely, can be visited and left freely and does not have the relationships needed for ownership, size, type of use, or landscape character. But City Public Open Space is not only based on that, but also there are qualitative values that must be maintained, namely access (achievement), compatibility (compatibility), views (views), identity (identity), sense (impression), and livability (convenience). This research produced a model for Merdeka Walk located in Merdeka Square, Medan.
\end{abstract}

\section{Keywords: Merdeka Square, Open space}

\begin{abstract}
Abstrak
Benar bahwa Lapangan Merdeka dapat diakses oleh semua orang, dapat digunakan untuk bermacam kegiatan. Dalam konteks perilaku, suatu ruangan dikatakan terbuka apabila memungkinkan orang untuk bertindak secara bebas, dapat dikunjungi dan ditinggalkan sekehendak hati dan tidak memiliki hubungan yang diperlukan untuk kepemilikian, ukuran, jenis penggunaan, atau karakter lansekap. Tapi Ruang Terbuka Publik Kota tidak hanya berpatokan pada hal tersebut, namun juga ada nilai-nilai kualitatif yang harus dipertahankan yaitu access (pencapaian), compatibility (kecocokan), view (pemandangan), identity (identitas), sense (kesan),dan livability (kenyamanan). Penelitian ini menghasilkan model untuk Merdeka Walk yang berada di Lapangan Merdeka Medan.
\end{abstract}

\section{Kata kunci: Lapangan Merdeka, Ruang terbuka publik}

\section{Pendahuluan}

Dari beberapa pemaparan beberapa tinjauan pustaka tersebut kemudian peneliti melihat Merdeka Walk yang berada pada sisi Barat Lapangan Merdeka telah menjadi salah satu permasalahan arsitektural terkait hubungannya dengan Lapangan Merdeka. Mulai dari keberadaanya (massa bangunan) yang menutupi pandangan (view) Lapangan Merdeka dari sisi Barat, kesan mahal (eksklusif) yang ditimbulkan sehingga membuat beberapa kalangan pengunjung merasa berbeda, orientasi nya yang membelakangi Lapangan Merdeka, dan sebagainya.

Namun permasalahan tersebut menjadi ironi, karena Merdeka Walk tersebut malah menjadi sebuah magnet tersendiri bagi para masyarakat Kota Medan maupun pendatang untuk mengunjungi wilayah Lapangan Merdeka.Banyaknya aneka kuliner yang tersedia dan lokasinya yang rimbun membuat Merdeka Walk menjadi daya tarik tersendiri baik bagi masyarakat Kota Medan mapupun pendatang dari luar Kota Medan.Belum lagi adanya kepentingan beberapa stakeholder yang mempunyai hak pada lokasi disekeliling Lapangan Merdeka.Oleh sebab itu diperlukan sebuah pengetahuan bagaimana seharusnya pemodan konsep desain Merdeka Walk agar tetap eksis dan tidak menghilangkan maupun mengurangi makna dan kualitas Lapangan Merdeka sebagai Ruang Terbuka Publik. 


\section{Metodologi}

Kegiatan penelitian ini dilakukan dengan menggunakan strategi penelitian studi kasus dengan kombinasi strategi (case studies and combined strategies). Secara garis besar jenis penelitian ini terdiri dari 2 (dua) kegiatan yaitu:

1. Melakukan studi kasus terhadap objek penelitian (Merdeka Walk Medan)

2. Mengkombinasikan beberapa tahapan strategi lanjutan. Adapun beberapa tahapan strategi lanjutan tersebut adalah :visual desain (visualisasi desain/pemodelan),teknik metode evaulatif ( pembobotan ) untuk mendapatkan model yang dipilih oleh para responden berdasarkan Teori Ruang Terbuka Publik.

\subsection{Metode Pengumpulan Data}

Data penelitian terdiri dari data primer dan data sekunder.Data primer adalah data yang diperoleh atau dikumpulkan oleh peneliti secara langsung dari sumber datanya.Data primer disebut juga sebagai data asli atau data baru yang memiliki sifat up to date. Untuk mendapatkan data primer, peneliti harus mengumpulkannya secara langsung. Teknik yang digunakan untuk mengumpulkan data primer dalam penelitian ini antara lain observasi, penyebaran kuesioner dan wawancara.

\subsection{Metode Analisis Data}

Metode analisa data dalam penelitian ini adalah merumuskan kriteria-kriteria yang didapatkan dari proses pengumpulan data sebelumnya yaitu :

1. Proses wawancara dari narasumber

2. Proses wawancara dari pengunjung lapangan merdeka

3. Kuesioner dari responden.

Data yang didapatkan dari proses pengumpulan data tersebut menjadi kiretria - kriteria yang akan digunakan dalam proses pemodelan konsep desain Merdeka Walk.

Narasumber dalam penelitian dibutuhkan untuk mendapatkan informasi-informasi penting yang akan mendukung keakuratan data dan proses analisa. Narasumber yang berpatisipasi dalam penelitian ini berasal dari 3 (tiga) sumber yaitu :

1. Pihak pengelola Merdeka Walk yakni, PT.Orange Indonesia Mandiri.

2. Kalangan Arsitek dalam hal ini berasal dari Dosen Fakultas Arsitektur Universitas Katolik St.Thomas

Sumatera Utara dan Arsitek Profesional yang mana keduanya memiliki pengalaman dan

pengetahuan tentang Merdeka Walk Medan.

3. Pihak Dinas Pertamanan Kota Medan

Format wawancara dibuat dalam bentuk pertanyaan-pertanyaan terbuka (open question) untuk mendapatkan sebanyak mungkin informasi yang berhubungan dengan tema penelitian. 


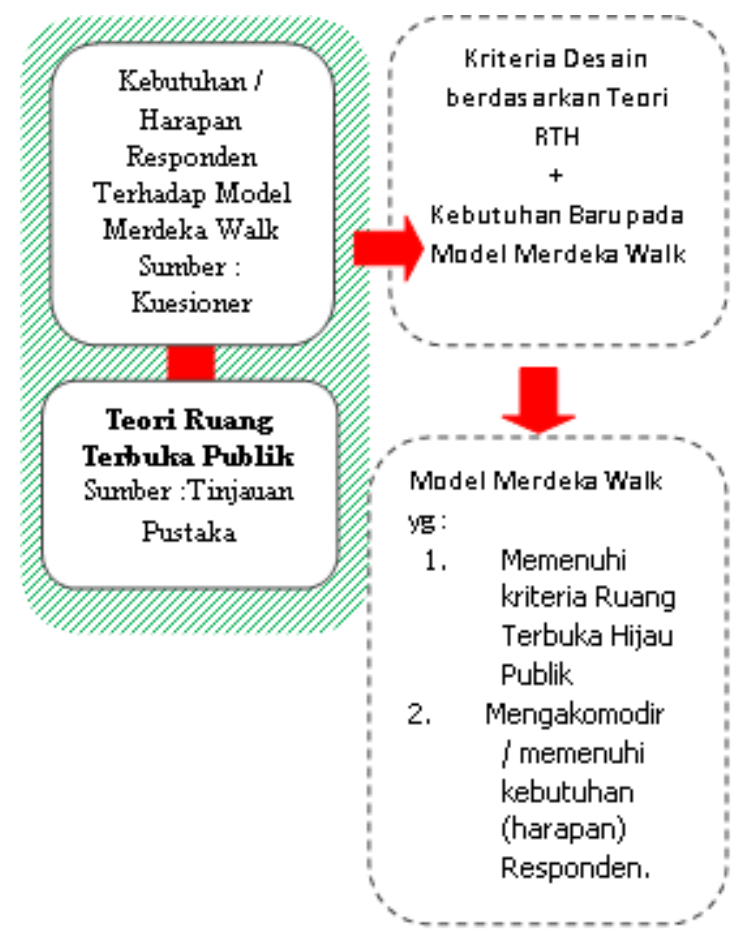

Diagram 1. Skema pengumpulan kriteria desain dan kebutuhan responden

Tabel 1. Rangkuman Apresiasi Responden berdasarkan kuesioner.

\section{No Rangkuman Arpesiasi Responden Berdasarkan Kuesioner Agar Model Merdeka Walk}

Skor I

Jumlah

\begin{tabular}{lll}
\hline $\mathbf{1}$ & Desain Merdeka Walk lebih meriah & 2 \\
\hline $\mathbf{2}$ & Desain Merdeka Walk unik dan menarik & 7 \\
& & 7 \\
\hline $\mathbf{3}$ & Menambah fasilitas umum \& sarana permainan gratis & 4 \\
\hline $\mathbf{4}$ & Membenahi ruang parkir & 3 \\
\hline $\mathbf{5}$ & Dapat di isi oleh beberapa jenis kuliner yang terjangkau (ekonomis) & 1 \\
\hline $\mathbf{6}$ & Memperhatikan unsur - unsur kenyamanan ruang luar & 5 \\
\hline $\mathbf{7}$ & Menyatu dengan Lapangan Merdeka / menjadi bagian pendukung & 1 \\
\hline $\mathbf{8}$ & Lapangan Merdeka & 3 \\
\hline $\mathbf{9}$ & Bagian service \& dapur tidak menghadap ke Lapangan Merdeka \\
\hline $\mathbf{1 0}$ & Desain yang tidak terlalu mewah sehingga sewa untuk tenant yang tidak & 6 \\
\hline $\mathbf{1 1}$ & Penahal dan tidak terkesan mahal bagi pengunjung & 1 \\
\hline $\mathbf{1 2}$ & Aksesnya ditambah dan lebih mudah serta "terbuka" untuk semua & 4 \\
\hline $\mathbf{1 4}$ & Harmonis dengan bangunan - bangunan disekiar lapangan Merdeka & 1 \\
\hline $\mathbf{1 5}$ & Tidak menutupi pandangan ke Lapangan Merdeka secara menyeluruh. & 13 \\
\hline $\mathbf{1 6}$ & Penataan papan reklame yang lebih teratur & 1 \\
\hline & & 3 \\
\hline $\mathbf{1 7}$ & Tersedianya ruang pejalan kaki yang lebih lebar dan nyaman \\
\hline $\mathbf{1 8}$ & Menghindari adanya bangunan - bangunan permanen, jika diperlukan, \\
\hline
\end{tabular}


bangunan yang digunakan bisa dibongkar pasang.

19 Mempertahankankan dan menambah vegetasi Lapangan Merdeka

$\mathbf{2 0}$ Tersedianya ruang - ruang komunal yang terbuka

$\mathbf{2 1}$ Jenis jajanan kuliner dengan konsep outdoor

22 Menyediakan outlet untuk Mc.Donald

Tabel.2 Key Attributes of Sucsessful Places

Sumber : Carmona et al dalam Rahmawati, 2010 p.37)

\begin{tabular}{|c|c|c|c|}
\hline Key Attributes & \multicolumn{2}{|c|}{ Intangibles ( Perwujudan ) } & \multirow{2}{*}{$\begin{array}{ll}\text { Measurements ( Tolak Ukur) } \\
\text { - } & \text { Crime statistics } \\
\text { - } & \text { Sanitation raiting } \\
\text { - } & \text { Building Conditions } \\
\text { - } & \text { Environment Data }\end{array}$} \\
\hline $\begin{array}{l}\text { Comfort dan } \\
\text { image }\end{array}$ & $\begin{array}{ll}\text { - } & \text { Safety } \\
\text { - } & \text { Charm } \\
\text { - } & \text { History } \\
\text { - } & \text { Attractiveness } \\
\text { - } & \text { Spirituality }\end{array}$ & $\begin{array}{ll}\text { - } & \text { Sittability } \\
\text { - } & \text { Walkability } \\
\text { - } & \text { Greenness } \\
\text { - } & \text { Cleanliness }\end{array}$ & \\
\hline $\begin{array}{l}\text { Accsess and } \\
\text { lingkage }\end{array}$ & $\begin{array}{ll}\text { - } & \text { Readibility } \\
\text { - } & \text { Walkability } \\
\text { - } & \text { Reliability } \\
\text { - } & \text { Continuity }\end{array}$ & $\begin{array}{ll}- & \text { Proximity } \\
\text { - } & \text { Connectedness } \\
\text { - } & \text { Convenience } \\
\text { - } & \text { Accsessibility }\end{array}$ & $\begin{array}{ll}\text { - } & \text { Traffic data } \\
\text { - } & \text { Model split } \\
\text { - } & \text { Transit Usage } \\
\text { - } & \text { Pedestrian Activity } \\
\text { - } & \text { Parking usage pattern } \\
\end{array}$ \\
\hline $\begin{array}{l}\text { Used and } \\
\text { Activity }\end{array}$ & $\begin{array}{ll}\text { - } & \text { Realness } \\
\text { - } & \text { Sustainibility } \\
\text { - } & \text { Specialness } \\
\text { - } & \text { Uniqueness } \\
\text { - } & \text { Affordiability } \\
\text { - } & \text { Fun }\end{array}$ & $\begin{array}{ll}\text { - } & \text { Activity } \\
\text { - } & \text { Usefulness } \\
\text { - } & \text { Celebration } \\
\text { - } & \text { Vitality } \\
\text { - } & \text { Indigenousness } \\
\text { - } & \text { Homegrown quality }\end{array}$ & $\begin{array}{ll}\text { - } & \text { Property Values } \\
\text { - } & \text { Rent Levels } \\
\text { - } & \text { Land-use patterns } \\
\text { - } & \text { Retail Sales } \\
\text { - } & \text { Local sales } \\
\text { - } & \text { Local business ownership }\end{array}$ \\
\hline Sociability & $\begin{array}{ll} & \text { Co-operation } \\
\text { - } & \text { Neighbourliness } \\
\text { - } & \text { Stewardship } \\
\text { - } & \text { Pride } \\
\text { - } & \text { Welcoming }\end{array}$ & $\begin{array}{ll}\text { - } & \text { Gossip } \\
\text { - } & \text { Diversity } \\
\text { - } & \text { Storytelling } \\
\text { - } & \text { Friendliness } \\
\text { - } & \text { Interactivity }\end{array}$ & $\begin{array}{ll}\text { - } & \text { Street life } \\
\text { - } & \text { Social networks } \\
\text { - } & \text { Evening use } \\
\text { - } & \text { Volunteerism } \\
\text { - } & \text { Number of women, children and elderly }\end{array}$ \\
\hline
\end{tabular}

\section{Analisa}

Kemudian ditemukanlah sebuah model Meredeka Walk yang baru. Model tersebut merupakan hasil dari penggabungan antara teori Ruang Terbuka Publik dan Apresiasi responden. Model ini secara umum terdiri atas beberapa fungsi diantaranya :

\section{Plasa Terbuka Utama ( Main Entrance )}

Plasa Utama ( Main Entrance ) menjadi lokasi palig sentral pada Merdeka Walk. Lokasi ini menjadi penerima utama para pengunjung sekaligus dapat menjadi Fasade maupun akses utama menuju ke Lapangan Merdeka. Plasa Utama dibiarkan kosong tanpa adanya tanaman maupun bangunan apapun sehingga view yang benar - benar terbuka dari Jalan Raden Saleh menuju Lapangan Merdeka.

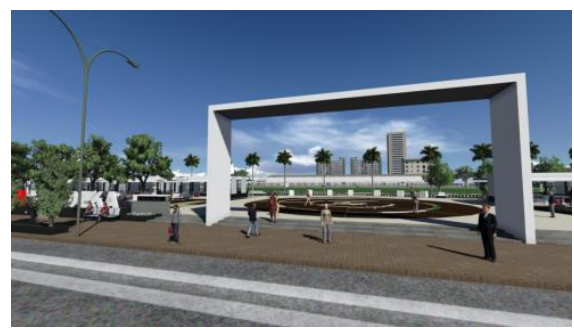

Gambar 8. Perspective Plasa Utama Sumber : Dokumentasi Pribadi 
2. Plasa Serbaguna Bagian Selatan

Plasa Serbaguna ( Plasa Selatan) diperuntukkan untuk Plasa yang dapat digunakan untuk bermacam - macam kegiatan publik. Plasa ini juga dijadikan akses masuk pengunjung dari sisi sebelah selatan yaitu dari Jalan Pulau Pinang sebagai perwujudan keterbukaan akses.Pada lokasi ini dilengkapi dengan tempat duduk umum, serta ATM Centre untuk publik.

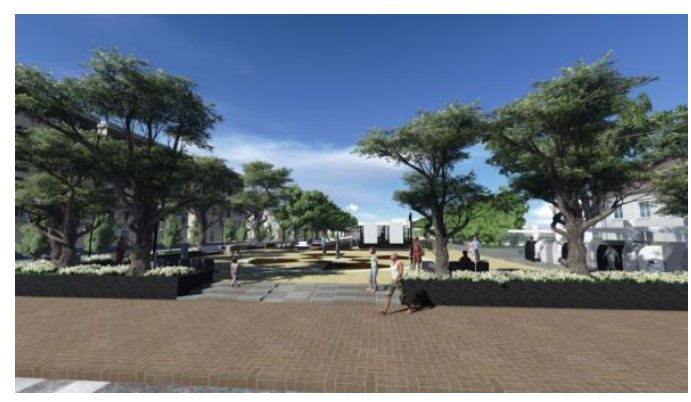

Gambar 9. Perspective Plasa Selatan Sumber : Dokumentasi Pribadi

3. Outlet - outlet Kuliner Tipe - A

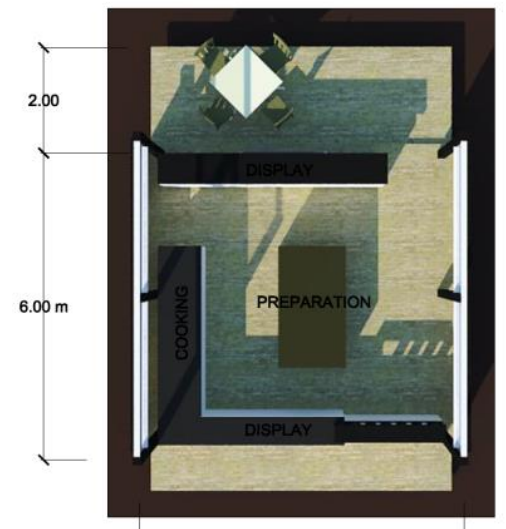

Gambar 10. Denah Outlet tipe - A Sumber : Dokumentasi Pribadi

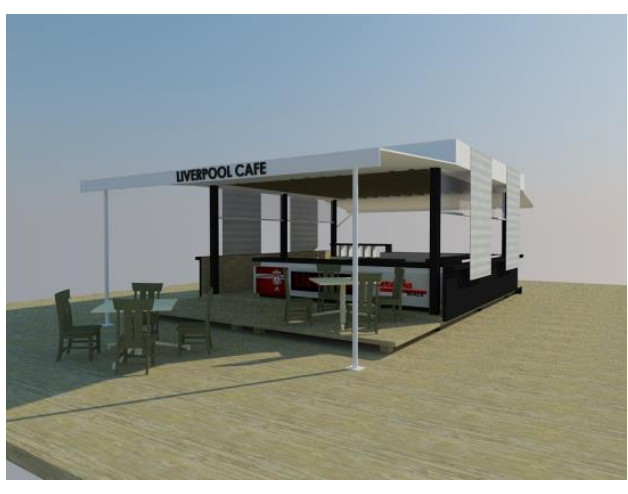

Gambar 11. Perspective Outlet - A Sumber : Dokumentasi Pribadi

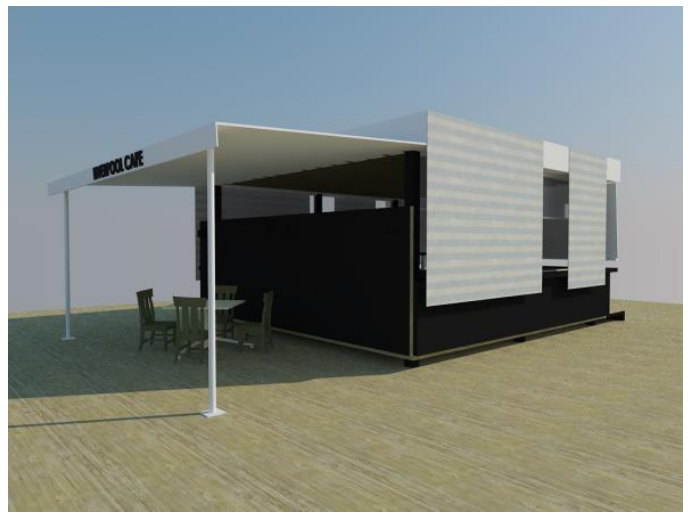

Gambar 12. Perspective Outlet - B pada posisi tutup

Sumber : Dokumentasi Pribadi 
4. Outlet - outlet Kuliner Tipe - B

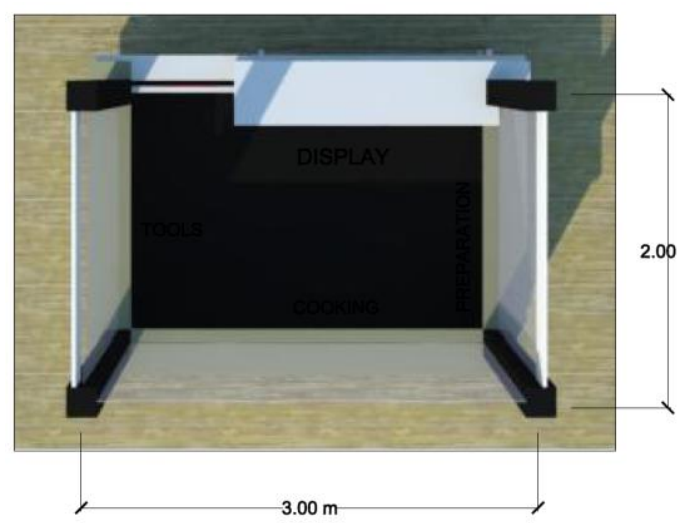

Gambar 13. Denah Outlet Tipe - B Sumber : Dokumentasi Pribadi

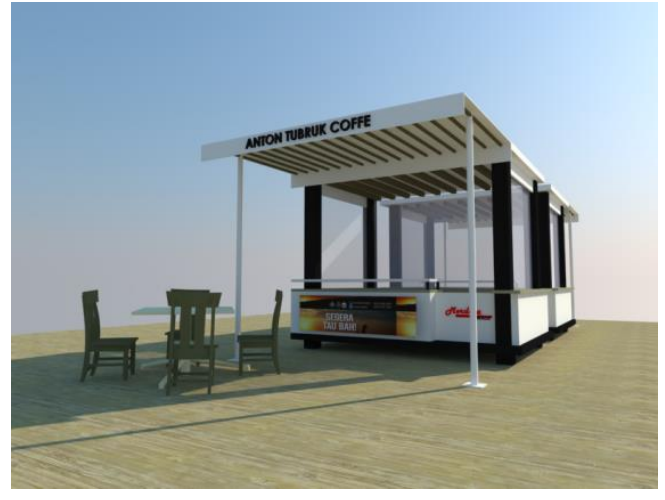

Gambar 14. Perspective Outlet Tipe - B Sumber : Dokumentasi Pribadi

\section{Jalur Pejalan Kaki}

Pada temuan Model Merdeka Walk yang baru terdapat 3 (tiga) layer pejalan kaki. Yaitu Jalur Pejalan Kaki Sidewalk (berbatasan dengan Jalan Umum), Jalur pejalan kaki ruang terbuka hijau pada area take away serta jalur pejalan kaki pada area makan pengunjung.

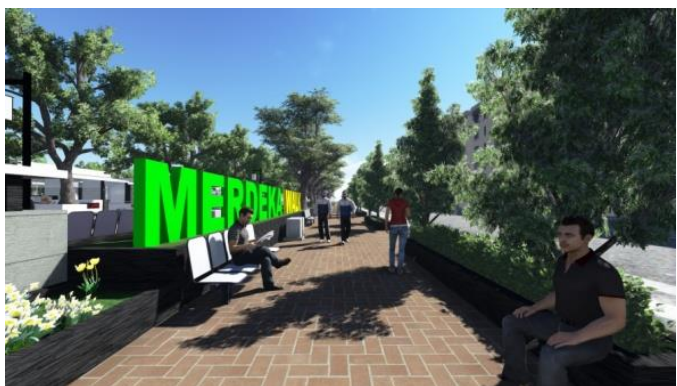

Gambar 15. Perspective jalur Pejalan Kaki Sidewalk (layer 1 )

Sumber : Dokumentasi Pribadi

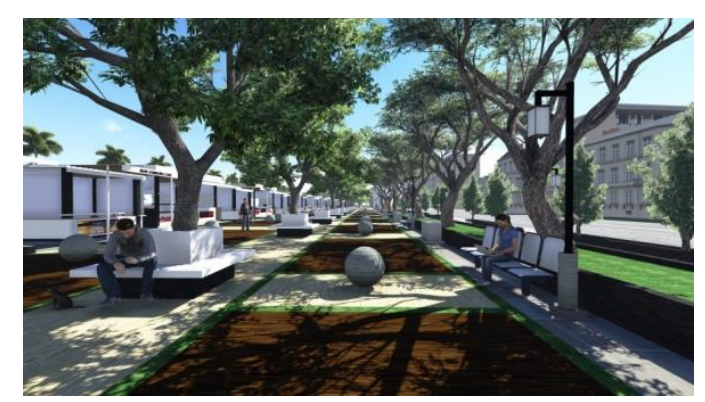

Gambar 16. Perspective jalur Pejalan Kaki area take away

Sumber : Dokumentasi Pribadi

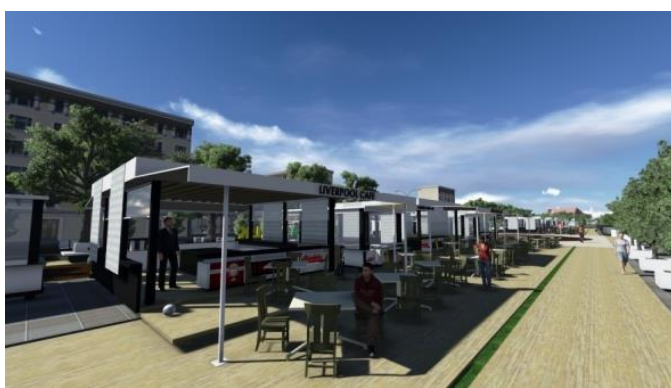

Gambar 17. Perspective jalur Pejalan Kaki area take away

Sumber : Dokumentasi Pribadi 


\section{Ruang Parkir}

Ruang parkir Merdeka Walk yang baru berada di sisi utara Lapangan Merdeka Medan. Pada bagian terluar area parkir ditanami beberapa tanaman penghias dan mempertahankan vegetasi yang ada.

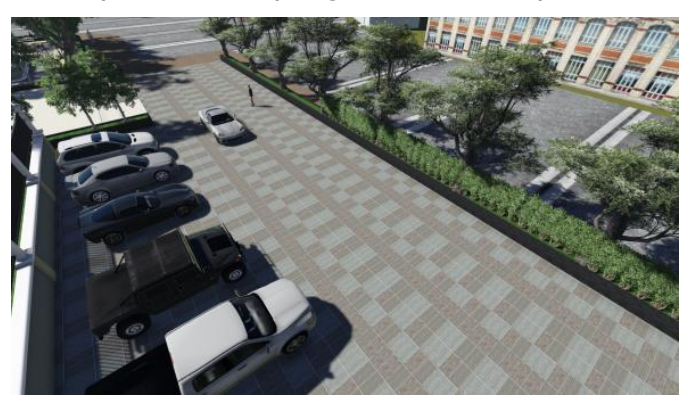

Gambar 18. Model Ruang Parkir Merdeka Walk Sumber : Dokumentasi Pribadi

7. Internet Gratis untuk publik (Hotspot gratis)

Dilengkapi juga dengan fasilitas Hotspot gratis untuk publik. Terdapat 2 (dua) bangunan terbuka yang berada diantara Outlet - outlet kuliner.

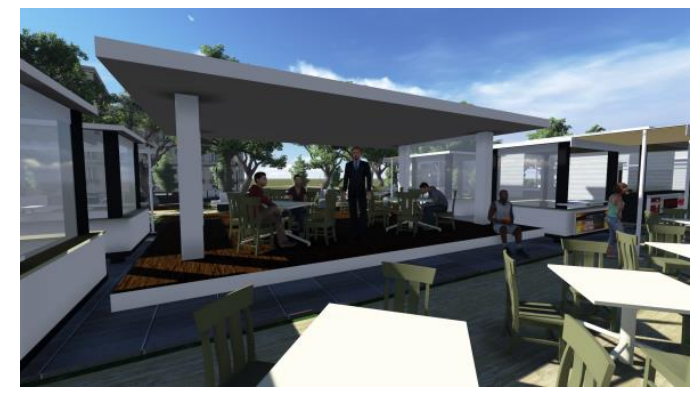

Gambar 19. Fasilitas Hotspot ara gratis. Sumber : Dokumentasi Pribadi

\section{Taman Lanjut Usia (LANSIA)}

Taman Lanjut Usia (LANSIA) diperuntukkan untuk para orang tua, sebagai salah satu perwujudan Ruang Terbuka Publik untuk semua tak terkecuali untuk para orang tua. Taman Lansia ini dilengkapi dengan sarana Jalur jalan refleksi, bangku - bangku santai, serta kolam air mancur, dan pohon - pohon peneduh.

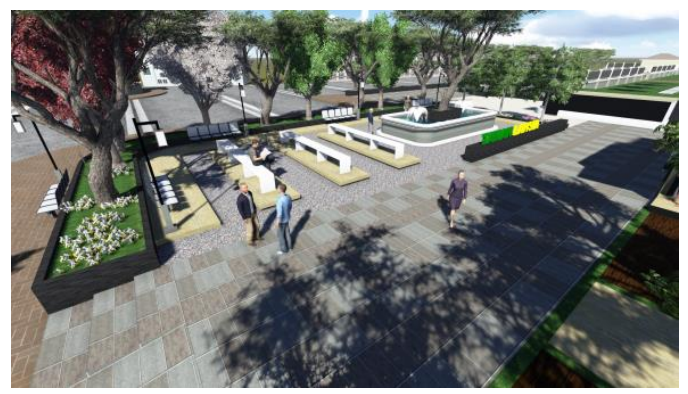

Gambar 20. Model Taman Lansia Sumber : Dokumentasi Pribadi 
Secara keseluruhan temuan dapat tergambar dalam gambar 21 dibawah ini :

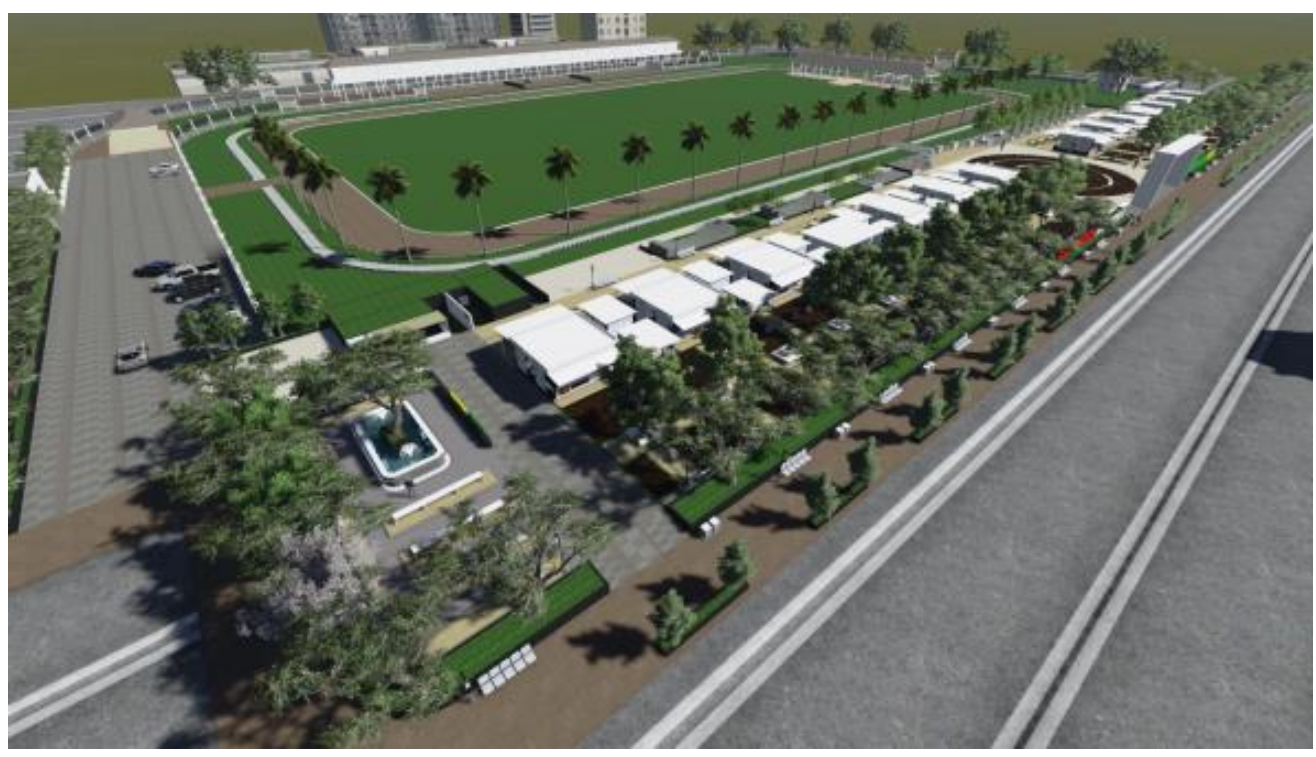

Gambar 21. Pandangan Mata Burung temuan Model Merdeka Walk Medan

Sumber : Dokumentasi Pribadi

\section{Kelebihan temuan Model Merdeka Walk dibandingkan dengan kondisi Existing.}

Model Merdeka Walk yang berhasil ditemukan, dapat menjadi pertimbangan maupun masukan untuk pengembangan maupun perbaikan Merdeka Walk maupun Lapangan Merdeka, karena hasil penelitian yang berupa Model Merdeka Walk ini , memiliki beberapa kelebihan dari Merdeka Walk yang ada saat ini, diantaranya :

1. Jalur Pedestrian lebih lebar dan teduh.

2. Terdapat lebih banyak ruang komunal / plasa terbuka pada Model Merdeka Walk yang baru.Contoh : Taman Lansia

3. Lebih terbuka dan menyatu dengan Lapangan Merdeka, sebagai Ruang Terbuka Hijau Publik.

4. Sudah mengakomodir kebutuhan / harapan responden mengenai Merdeka Walk Medan.

5. Furniture Pelengkap pedestrian lebih banyak ( mis. Bangku taman, lampu taman, dll).

6. Layer terluar pada temuan Model Merdeka Walk merupakan Ruang Terbuka Hijau,yang merupakan bagian dari Lapangan Merdeka sehingga Lapangan Merdeka sudah terbuka.

\section{Kesimpulan}

Adapun saran yang dapat diberikan dari kegiatan penelitian ini adalah sebagai berikut :

1. Tempat jajanan berupa wisata Kuliner seperti Merdeka Walk agar dapat diperuntukkan bagi semua kalangan masyarakat baik secara langsung maupun tidak langsung.

2. Merdeka Walk agar tidak terpisah dengan Lapangan Merdeka karena merupakan bagian dari sarana pendukung dari Lapangan Merdeka.

3. Lapangan Merdeka dibenahi baik dalam penataannya serta fasilitas pendukung yang diperuntukkan untuk publik.

4. Agar dibuat Pemodelan Lapangan Merdeka menyusul Pemodelan Merdeka Walk yang telah dilakukan.

5. Hasil Penelitian ini yang berupa temuan Model Merdeka Walk dapat menjadi pertimbangan bagi Pemerintah Kota (PEMKO) Medan maupun pihak lainnya jika ada rencana pembenahan Merdeka Walk yang ada saat ini. 


\section{Daftar Pustaka}

Design for Shopping Center. Mc. Graw-Hill Book Company. New York

Ashihara, Yoshinibu . 1983. Exterior Design in Architecture ,Van Nostrand Company, New York

Panitia Teknik Standardisasi Bidang Bahan Konstruksi Bangunan dan Rekayasa Sipil, 2009. Pedoman Penyediaan dan Pemanfaatan Prasarana dan Sarana Ruang Pejalan Kaki di Perkotaan, Direktorat Penataan Ruang, Departemen Pekerjaan Umum, Jakarta, Indonesia.

Panitia Teknik Standarisasi Bidang Jalan dan Jembatan, 1999. Pedoman Teknis Persyaratan Aksesibilitas pada Jalan Umum ,PT. Mediatama Saptakarya, Departemen Pekerjaan Umum Bina Marga , Jakarta Indonesia.

Panitia Teknik Standarisasi Kementrian Pekerjaan Umum, 2014. Peraturan Menteri Pekerjaan Umum No. 03-PRT-M2014 Tentang Pedoman Perencanaan, Penyediaan, dan Pemanfaatan Prasarana dan Sarana Jaringan Pejalan Kaki di Kawasan Perkotaan, Kementrian Pekerjaan Umum Republik Indonesia , Jakarta ,Indonesia. 